\title{
Programmable co-delivery of the immune checkpoint inhibitor NLG919 and chemotherapeutic doxorubicin via a redox-responsive immunostimulatory polymeric prodrug carrier
}

\author{
Jing-jing SUN $N^{1,2,3, \# \text {, Yi-chao CHEN }}{ }^{1,2,3, \#}$, Yi-xian HUANG ${ }^{1,2,3}$, Wen-chen ZHAO ${ }^{2}$, Yan-hua LIU ${ }^{4}$, Raman VENKATARAMANAN ${ }^{2}$, \\ Bin-feng $\mathrm{LU}^{3,5}$, Song $\mathrm{LI}^{1,2,3, *}$ \\ ${ }^{1}$ Center for Pharmacogenetics, ${ }^{2}$ Department of Pharmaceutical Sciences, School of Pharmacy; ${ }^{3}$ University of Pittsburgh Cancer \\ Institute, University of Pittsburgh, Pittsburgh, PA 15261, USA; ${ }^{4}$ Department of Pharmaceutics, School of Pharmacy, Ningxia Medical \\ University, Yinchuan 750004, China; ${ }^{5}$ Department of Immunology, School of Medicine, University of Pittsburgh, Pittsburgh, PA 15261, \\ USA
}

\begin{abstract}
To achieve synergistic therapeutic efficacy and prevent cancer relapse, chemotherapy and immunotherapy have been combined as a new modality for tumor treatment. In this work, we designed a redox-responsive immunostimulatory polymeric prodrug carrier, PSSN10, for programmable co-delivery of an immune checkpoint inhibitor NLG919 (NLG) and a chemotherapeutic doxorubicin (DOX). NLG-containing PSSN10 prodrug polymers were self-assembled into nano-sized micelles that served as a carrier to load DOX (DOX/ PSSN10 micelles). DOX/PSSN10 micelles displayed spherical morphology with a size of $\sim 170 \mathrm{~nm}$. DOX was effectively loaded into PSSN10 micelles with a loading efficiency of 84.0\%. In vitro DOX release studies showed that rapid drug release could be achieved in the highly redox environment after intracellular uptake by tumor cells. In 4T1.2 tumor-bearing mice, DOX/PSSN10 micelles exhibited greater accumulation of DOX and NLG in the tumor tissues compared with other organs. The PSSN10 carrier dose-dependently enhanced T-cell immune responses in the lymphocyte-Panc02 co-culture experiments, and significantly inhibited tumor growth in vivo. DOX/PSSN10 micelles showed potent cytotoxicity in vitro against 4T1.2 mouse breast cancer cells and PC-3 human prostate cancer cells comparable to that of DOX. In 4T1.2 tumor-bearing mice, DOX/PSSN10 mixed micelles (5 mg DOX/kg, iv) was more effective than DOXIL (a clinical formulation of liposomal DOX) or free DOX in inhibiting the tumor growth and prolonging the survival of the treated mice. In addition, a more immunoactive tumor microenvironment was observed in the mice treated with PSSN10 or D0X/ PSSN10 micelles compared with the other treatment groups. In conclusion, systemic delivery of DOX via PSSN10 nanocarrier results in synergistic anti-tumor activity.
\end{abstract}

Keywords: NLG919; checkpoint; immunotherapy; prodrug micelles; doxorubicin; co-delivery; 4T1.2 mouse breast cancer cells; PC-3 human prostate cancer cells

Acta Pharmacologica Sinica (2017) 38: 823-834; doi: 10.1038/aps.2017.44; published online 8 May 2017

\section{Introduction}

Chemotherapy is one of the most widely used treatments for cancers. Although chemotherapeutic agents kill tumor cells mainly through cytostatic and/or cytotoxic effects, a large body of evidence suggests that chemotherapy-elicited immune responses also contribute to overall antitumor activity ${ }^{[1]}$.

\footnotetext{
\# These authors contributed equally to this work.

* To whom correspondence should be addressed. E-mail sol4@pitt.edu

Received 2016-12-02 Accepted 2017-02-12
}

However, the overall effect of chemotherapy is limited by the various negative regulatory mechanisms, such as inhibitory immune checkpoints, deployed by tumors to evade immune surveillance and suppress immune responses ${ }^{[2,3]}$. For example, cytotoxic T-lymphocyte-associated protein 4 (CTLA-4) is an immune checkpoint receptor expressed by activated $\mathrm{T}$ cells and transmits an inhibitory signal to $\mathrm{T}$ cells ${ }^{[4]}$. Tumors exploit CTLA-4 signaling to inhibit the initiation of an immune response, resulting in decreased T-cell activation and proliferation $^{[5]}$. Like CTLA-4, programmed cell death protein 1 (PD-1) receptor is expressed on the surface of activated $\mathrm{T}$ cells. Its 
ligand PD-L1, which is overexpressed by tumor cells, interacts with PD-1, leading to inhibition of cytotoxic T cells. Tumor cells utilize the PD-L1/PD-1 pathway to evade detection and inhibit the immune response ${ }^{[6-8]}$. To enhance anti-tumor immunity and prevent cancer relapse, checkpoint blockade immunotherapy and chemotherapy have been combined as an attractive modality for cancer treatment ${ }^{[9-11]}$.

Indoleamine 2,3-dioxygenase-1 (IDO1) is an immunosuppressive protein that helps tumors evade the immune system and facilitates tumor growth and metastasis ${ }^{[12-14]}$. IDO1 is overexpressed by most tumors and mediates the degradation of the essential amino acid tryptophan (Trp) to kynurenine (Kyn) and other metabolites, resulting in suppression of effector $\mathrm{T}$ cells and promotion of regulatory $\mathrm{T}$ cell proliferation ${ }^{[15]}$. Thus, blocking the function of IDO1 is a promising strategy to reactivate the immune response against cancer ${ }^{[16]}$.

NLG919 is a nontoxic IDO1-selective inhibitor that blocks IDO-mediated immune suppressive pathways and leads to tumor regression in preclinical model ${ }^{[17]}$. Inhibition of the IDO pathway can act synergistically with chemotherapy ${ }^{[18,19]}$. However, the success of an immunochemotherapy that combines NLG919 with a chemotherapeutic drug is limited by the lack of a strategy to effectively co-deliver the two therapeutics to the tumors. Co-loading of the two agents into a nanocarrier may meet with limited success due to the differences in their physiochemical properties. In addition, tempo-spatial control of the release of the different drugs is difficult; all of the loaded drug is often released simultaneously.

To solve these problems, our group previously developed a PEG-NLG conjugate (PEG2k-Fmoc-NLG) as a prodrug carrier for co-delivery of NLG919 and the chemotherapeutic drug paclitaxel (PTX) ${ }^{[20]}$. The immune-enhancing function of NLG and the tumor killing effect of PTX synergistically contributed to increased anti-tumor efficacy. In this work, we further improved the NLG-based prodrug system by increasing the units of NLG per prodrug molecule via reversible additionfragmentation chain transfer (RAFT) polymerization technology (Supplementary Figure S1). The new PSSN10 system consists of a POEG hydrophilic block and a PNLG hydrophobic block with a number of NLG919 motifs attached via redoxsensitive linkages (Figure 1). The PNLG hydrophobic block in the polymeric carrier not only provides immunostimulatory properties but also facilitates the encapsulation of doxorubicin (DOX), a potent chemotherapeutic agent that induces immunogenic tumor cell death ${ }^{[21]}$. NLG919 and DOX are incorporated into this system through chemical conjugation and physical "loading", respectively, which allows the programmed release of DOX and NLG919 in the tumors. In addition, a disulfide linkage was introduced between NLG919 and the polymer backbone to facilitate the cleavage of NLG919 from the polymeric carrier at tumor sites. The effect of the PSSN10 polymer on IDO activity and T cell proliferation was tested. The efficiency of the nanocarrier in selective delivery of DOX to tumors was examined. The synergistic antitumor activity of DOX formulated in the immunostimulatory nanocarrier and the underlying mechanism were also investigated.

\section{Materials and methods \\ Materials}

DOX $\cdot \mathrm{HCl}$ was purchased from LC Laboratories. 4-Nitrophenyl chloroformate was purchased from Acros. Dulbecco's modified Eagle's medium (DMEM), trypsin-EDTA solution, 3-(4,5-dimethylthiazol-2-yl)-2,5-diphenyl tetrazolium bromide (MTT), Triton X-100 and Hoechst 33342 were purchased from Sigma-Aldrich. Penicillin-streptomycin solution and fetal bovine serum (FBS) were purchased from Invitrogen. 2-Azobis(isobutyronitrile) (AIBN, Sigma-Aldrich) was purified by recrystallization in anhydrous ethanol ${ }^{[22]}$. $N, N^{\prime}-(t-$ butyoxycarbonyl)cystamine (MBC) ${ }^{[23]}$ and POEG macroCTA ${ }^{[24]}$ were prepared according to the literature. All other reagents were of analytical or chromatographic grade.

\section{Synthesis of 4-nitrophenyl-actived NLG919 $\left(\mathrm{NLG}^{-\mathrm{NO}_{2}}\right)$}

NLG919 (225 mg, $0.80 \mathrm{mmol}$ ), 4-nitrophenyl chloroformate (327 mg, $1.6 \mathrm{mmol}$ ) and $400 \mu \mathrm{L}$ of N,N-diisopropylethylamine (DIPEA) were dissolved in $8 \mathrm{~mL}$ of anhydrous dichloromethane (DCM) and stirred overnight at room temperature. The product $\left(\mathrm{NLG}-\mathrm{NO}_{2}\right.$ ) was obtained by column chromatography purification.

\section{Synthesis of POEG-b-PMBC polymers}

MBC monomer (144 mg, $0.45 \mathrm{mmol}$ ), POEG macroCTA (175 $\mathrm{mg}, 0.0194 \mathrm{mmol})$, AIBN (1 mg, $0.0062 \mathrm{mmol})$ and $1 \mathrm{~mL}$ of 1,4-dioxane were added to a Schlenk tube and deoxygenated by free-pump-thawing three times. The Schlenk tube was then immersed in an oil bath at $90^{\circ} \mathrm{C}$. After $24 \mathrm{~h}$, the mixture was precipitated in diethyl ether 3 times to yield the POEG- $b$ PMBC polymers.

\section{Synthesis of PSSN10 polymers}

POEG- $b$-PMBC polymers were deprotected in a mixture of TFA/DCM $(1 / 1, v / v)$ at room temperature for $2 \mathrm{~h}$, precipitated in cold diethyl ether 3 times, and dried under vacuum to give the Boc-deprotected polymer products. Then, the assynthesized Boc-deprotected polymers $(118 \mathrm{mg}, 0.01 \mathrm{mmol})$ and NLG-NO $\mathrm{N}_{2}(179 \mathrm{mg}, 0.4 \mathrm{mmol})$ were dissolved in $2 \mathrm{~mL}$ of DMF with $200 \mu \mathrm{L}$ of DIPEA. After stirring at room temperature for $24 \mathrm{~h}$, the reaction mixture was precipitated in diethyl ether 3 times. The final product, PSSN10, was obtained after vacuum drying.

\section{Preparation of blank and DOX-loaded micelles}

The blank and DOX-loaded PSSN10 micelles were prepared by a dialysis method. DOX $\cdot \mathrm{HCl}$ was first dissolved in methanol at a concentration of $5 \mathrm{mg} / \mathrm{mL}$ with triethylamine (3 equiv) to remove $\mathrm{HCl}$. PSSN10 polymer was dissolved in THF at a concentration of $50 \mathrm{mg} / \mathrm{mL}$. Then, the DOX solution was mixed with the PSSN10 polymer solution at a DOX/ polymer mass ratio of 1:20, followed by dropwise addition of $0.5 \mathrm{~mL}$ of PBS. After removing solvent under reduced pressure, the solution was dialyzed against PBS overnight (MWCO $3.5 \mathrm{kDa}$ ). Blank micelles were similarly prepared except that no DOX was added. For determination of the DOX concen- 
A
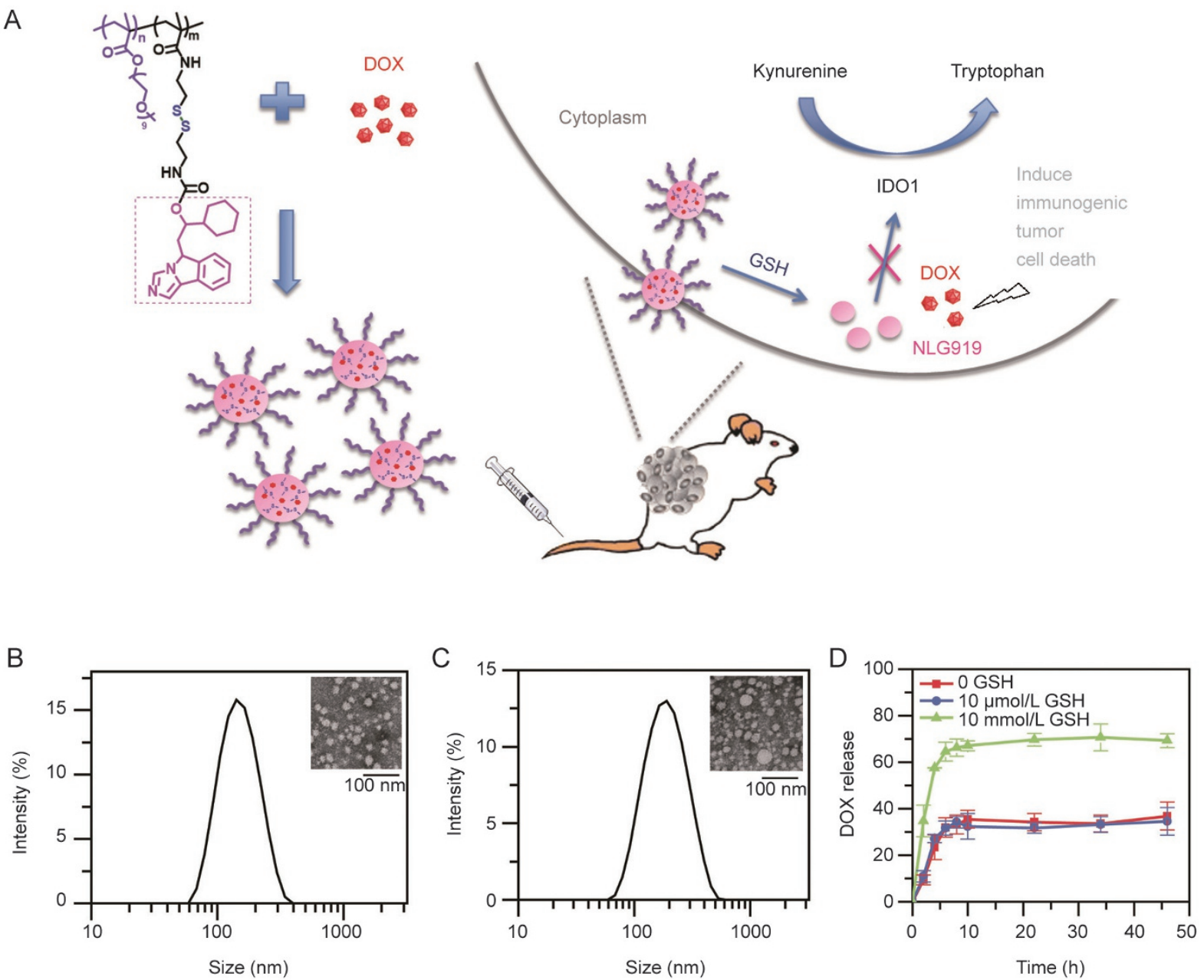

Figure 1. (A) Schematic illustration of the redox-responsive immunostimulatory PSSN10 polymeric prodrug carrier for co-delivery of NLG919 and D0X. (B) The particle size distribution of PSSN10 micelles measured by DLS (Inset: TEM image of PSSN10 micelle using negative staining; scale bar is 100 nm). (C) The particle size distribution of DOX/PSSN10 mixed micelles measured by DLS (Inset: TEM image of DOX/PSSN10 mixed micelles using negative staining; scale bar is $100 \mathrm{~nm}$ ). (D) The in vitro release profiles of DOX from the DOX/PSSN10 mixed micelles in PBS with different GSH concentrations (0, $10 \mu \mathrm{mol} / \mathrm{L}, 10 \mathrm{mmol} / \mathrm{L})$ at $37^{\circ} \mathrm{C}$.

tration, DOX-loaded micelles were dissolved in DMSO and detected by fluorescence spectroscopy with excitation at 490 $\mathrm{nm}$. Drug loading capacity (DLC) and drug loading efficiency (DLE) were calculated according to the following formula:

DLC $(w t \%)=($ weight of loaded drug/weight of input polymer+drug $) \times 100 \%$

DLE $(\%)=($ weight of loaded drug/weight of drug in feed) $\times 100 \%$

\section{Critical micelle concentration (CMC) measurement}

The CMC value of PSSN10 micelles was measured using Nile red as a fluorescence probe ${ }^{[25]}$. Briefly, $10 \mu \mathrm{L}$ of a $0.05 \mathrm{mg} / \mathrm{mL}$ stock solution of Nile red in DCM was added to each tube. After the solvent was completely evaporated, PSSN10 solution in PBS ranging from $1.0 \times 10^{-4}$ to $5 \times 10^{-1} \mathrm{mg} / \mathrm{mL}$ was added. The mixtures were incubated overnight and then evaluated by fluorescence spectrometry.

\section{Polymer and micelle characterization}

${ }^{1} \mathrm{H}$ NMR spectroscopy was performed on a Varian-400 FTNMR spectrometer $(400.0 \mathrm{MHz})$ with $\mathrm{CDCl}_{3}$ and DMSO- $d_{6}$ as the solvent. The molecular weight $\left(M_{\mathrm{n}}\right.$ and $\left.M_{\mathrm{w}}\right)$ and distribution $\left(M_{\mathrm{w}} / M_{\mathrm{n}}\right)$ of the synthesized polymers were measured by gel permeation chromatography (GPC) with a Waters 2414 refractive index detector. A series of polystyrene standards with a narrow molecular weight distribution were applied to calibrate the GPC elution traces. Tetrahydrofuran (THF) was used as the eluent at a flow rate of $1.0 \mathrm{~mL} / \mathrm{min}$ at $35^{\circ} \mathrm{C}$, and a series of commercial polystyrene standards were used for the calibration. The size distribution and morphology of blank and drug-loaded micelles were examined by dynamic light scattering (DLS, Malvern Zeta Nanosizer) and transmission electron microscopy (TEM, negative staining method), respectively. 


\section{In vitro DOX release}

The in vitro DOX release profiles of DOX-loaded PSSN10 micelles were examined under different GSH concentrations $(0,10 \mu \mathrm{mol} / \mathrm{L}, 10 \mathrm{mmol} / \mathrm{L})$. DOX-loaded micelles with a DOX concentration of $0.25 \mathrm{mg} / \mathrm{mL}$ were transferred into a dialysis bag (MWCO=3.5 kDa, Spectrum Laboratories) and immersed in a tank containing $50 \mathrm{~mL}$ of DPBS ( $\mathrm{pH}=7.4)$ with different GSH concentrations $(0,10 \mu \mathrm{mol} / \mathrm{L}, 10 \mathrm{mmol} / \mathrm{L})$ with gentle shaking at $37^{\circ} \mathrm{C}$. At specific time intervals, $4 \mathrm{~mL}$ of PBS solution outside the dialysis bag was withdrawn and replaced with $4 \mathrm{~mL}$ fresh solution. The amount of DOX released was determined by fluorescence spectrometry as described above.

\section{Cell culture}

Mouse metastatic breast cancer cells (4T1.2), human prostatic carcinoma cells (PC3) and human cervical cancer cells (HeLa) were cultured in DMEM culture medium containing 10\% (v/v) fetal bovine serum, $100 \mathrm{IU} / \mathrm{mL}$ penicillin and $100 \mu \mathrm{g} / \mathrm{mL}$ streptomycin at $37^{\circ} \mathrm{C}$ in a humidified $5 \% \mathrm{CO}_{2}$ atmosphere.

\section{In vitro IDO inhibition}

The IDO inhibitory activity of PSSN10 was tested by an IDO assay ${ }^{[26]}$. Briefly, HeLa cells were plated in a 96-well plate $\left(5 \times 10^{3}\right.$ cells/well) and allowed to grow overnight. Recombinant human IFN-ץ (50 ng/mL) was then added to each well, followed by various concentrations of PSSN10 or free NLG919 (NLG919 concentrations: $50 \mathrm{nmol} / \mathrm{L}-20 \mu \mathrm{mol} / \mathrm{L}$ ). After incubation for $48 \mathrm{~h}, 150 \mu \mathrm{L}$ of the supernatant was transferred to a new 96 -well plate. Then, $75 \mu \mathrm{L}$ of $30 \%$ trichloroacetic acid was added, and the mixture was incubated at $50^{\circ} \mathrm{C}$ for $30 \mathrm{~min}$ to hydrolyze $\mathrm{N}$-formylkynurenine to kynurenine. For the colorimetric assay, the supernatants were transferred to a new 96-well plate and incubated with an equal volume of Ehrlich reagent $(2 \%$ p-dimethylamino-benzaldehyde in glacial acetic acid, $w / v$ ) for $10 \mathrm{~min}$ at room temperature. The reaction product was measured at $490 \mathrm{~nm}$ by a plate reader. For HPLC-MS detection (Wastes Alliance 2695 Separation Module combined with Waters Micromass Quattro Micro ${ }^{\mathrm{TM}}$ API MS detector), the plate was centrifuged for $10 \mathrm{~min}$ at 2500 rounds per minute, and $100 \mu \mathrm{L}$ of the supernatant from each well was collected for tryptophan and kynurenine assays.

\section{T-cell proliferation study}

A lymphocyte-Panc02 cell co-culture experiment was performed to determine whether PSSN10 can reverse IDO1mediated inhibition of T-cell proliferation ${ }^{[27]}$. Murine Panc02 cells were stimulated by IFN-ץ $(50 \mathrm{ng} / \mathrm{mL})$ to induce IDO expression and then irradiated (6000 rad) before coculture. Splenocyte suspensions were generated from BALB/c mice by passage through nylon wool columns after lysis of red blood cells. IFN- $\gamma$-stimulated Panc02 cells $\left(1 \times 10^{5}\right.$ cells/well $)$ were mixed with splenocytes $\left(5 \times 10^{5}\right.$ cells/well, pre-stained with 5-(and 6)-carboxyfluorescein diacetate (CFSE)) in a 96-well plate. Various concentrations of PSSN10 and NLG919 were added to the cells. Then, $100 \mathrm{ng} / \mathrm{mL}$ anti-CD3 (clone 2C11) and $10 \mathrm{ng} / \mathrm{mL}$ mouse recombinant IL-2 were added to the cocultures. The proliferation of $\mathrm{CD}^{+}$and $\mathrm{CD}^{+} \mathrm{T}$ cells was measured by flow cytometric analysis after $3 \mathrm{~d}$ of coculture.

\section{In vitro cytotoxicity assay}

4T1.2 and PC3 cancer cell lines were used for in vitro cytotoxicity study. Cells were seeded in 96-well plates at densities of $1.5 \times 10^{3}(4 \mathrm{~T} 1.2)$ and $3 \times 10^{3}$ (PC3) cells/well. After incubation for $24 \mathrm{~h}$, the cells were treated with free DOX, PSSN10 and DOX/PSSN10 micelles in a gradient concentration. After incubation for $72 \mathrm{~h}$, the cell viability was measured via MTT assay as reported before ${ }^{[28]}$. Untreated cells were included as a control.

\section{Cell uptake and intracellular trafficking}

$4 \mathrm{~T} 1.2$ cells were cultured in glass-bottom dishes $\left(1 \times 10^{5}\right.$ cells $/$ dish) for $24 \mathrm{~h}$ and then treated with DOX/PSSN10 micelles and free DOX (DOX concentration: $20 \mu \mathrm{g} / \mathrm{mL}$ ) in FBS-free culture medium. After $4 \mathrm{~h}$, the cells were stained with Hoechst 33342 for $20 \mathrm{~min}$ and washed with PBS 3 times. The fluorescence images were obtained using a confocal laser scanning microscope (CLSM, FluoView 1000, Olympus, Japan).

\section{Animals}

Female BALB/c mice (6-8 weeks) and C57BL/6 mice (4-6 weeks) were purchased from Charles River (Davis, CA, USA). All animals were housed under pathogen-free conditions according to AAALAC guidelines. All animal-related experiments were performed in full compliance with institutional guidelines and approved by the Animal Use and Care Administrative Advisory Committee at the University of Pittsburgh.

\section{Quantification of the Trp/Kyn ratio in plasma and tumor tissues} The kynurenine to tryptophan ratios in plasma or tumors in 4T1.2 tumor-bearing mice were examined by HPLC-MS/ MS as an indication of IDO enzyme activity ${ }^{[29]}$. BALB/c mice bearing 4T1.2 tumors of $\sim 50 \mathrm{~mm}^{3}$ were treated with DPBS, DOX, DOXIL, PSSN10, DOX/PSSN10 at a DOX dosage of 5 $\mathrm{mg} / \mathrm{kg}$ via the tail vein once every $3 \mathrm{~d} 3$ times. One day after the last treatment, plasma and tumor samples were harvested. Plasma samples were mixed with methanol (plasma:methanol, $1: 2.5, v / v)$ and centrifuged at 14500 rounds per minute for 15 min. Supernatants were collected for HPLC-MS quantification of kynurenine and tryptophan.

Tumor samples were homogenized in water, and the homogenates were mixed with acetonitrile $(1: 1, v / v)$ and centrifuged. The supernatants were transferred to clean tubes. Equal volumes of methanol were added to precipitate proteins, and supernatants were collected for HPLC-MS measurement.

\section{Plasma pharmacokinetics and tissue distribution}

Female BALB/c mice (5 mice/group) were iv administered DOX $\cdot \mathrm{HCl}$ and DOX-loaded PSSN10 micelles at a DOX dose of $5 \mathrm{mg} / \mathrm{kg}$. Blood samples were collected at different time 
points ( $3 \mathrm{~min}, 10 \mathrm{~min}, 30 \mathrm{~min}, 1 \mathrm{~h}, 2 \mathrm{~h}, 4 \mathrm{~h}, 8 \mathrm{~h}$ and $12 \mathrm{~h}$ ) and centrifuged at 2500 rounds per minute for $15 \mathrm{~min}$. A $350-\mu \mathrm{L}$ volume of acetonitrile was added to the plasma and centrifuged at 12000 rounds per minute for $5 \mathrm{~min}$. Then, the supernatants were collected and dried under airflow. The DOX concentrations in the samples were analyzed by HPLC. The pharmacokinetic parameters were calculated based on a noncompartment model by Phoenix WinNonlin.

For the tissue distribution study, DOX $\cdot \mathrm{HCl}$ and DOX/ PSSN10 micelles were iv injected into female BALB/c mice bearing 4T1.2 tumors at a DOX dose of $5 \mathrm{mg} / \mathrm{kg}$. At 24-h post injection, the mice were sacrificed, and the major organs were excised. The tissues were weighed and homogenized in $2 \mathrm{~mL}$ of solvent (acetonitrile: $\mathrm{H}_{2} \mathrm{O}=1: 1, v / v$ ). The samples were centrifuged at 3500 rounds per minute for $10 \mathrm{~min}$, and the supernatants were collected and dried under airflow. The residues were then dissolved in $200 \mu \mathrm{L}$ of solvent (methanol: $\mathrm{H}_{2} \mathrm{O}=1: 1$, $v / v$ ) and centrifuged at 14500 rounds per minute for 10 min. The DOX concentrations in the clear supernatants were detected by HPLC.

\section{In vivo therapeutic efficacy}

Female BALB/c mice bearing 4T1.2 tumors were iv administered saline, free DOX, blank PSSN10 micelles or DOX/ PSSN10 mixed micelles ( $\mathrm{mg}$ DOX $/ \mathrm{kg}$ ) once every two days 3 times. Tumor volumes were calculated according to the formula $\left(\mathrm{L} \times \mathrm{W}^{2}\right) / 2$, in which $\mathrm{L}$ is the longest and $\mathrm{W}$ is the shortest tumor diameter $(\mathrm{mm})$, and presented as the relative tumor volume (the tumor volume at a given time point divided by the tumor volume prior to the first treatment). In addition, changes in the body weights of all mice were monitored. At the completion of the experiment, tumor tissues were excised, fixed with $10 \%$ formaldehyde and embedded in paraffin. Tissues sliced at $5 \mu \mathrm{m}$ were stained by hematoxylin and eosin (H\&E) and observed by a Zeiss Axiostar plus Microscope (PA, USA). The Kaplan-Meier survival of the tumor-bearing mice $(n=8)$ was followed within $45 \mathrm{~d}$. Mice were considered dead either when the mice died during treatment or when the tumor volume reached $\sim 1000 \mathrm{~mm}^{3}$.

\section{Quantification of tumor-infiltrating lymphocytes}

The immune cell populations in the tumors following various treatments were measured by flow cytometry ${ }^{[30]}$. One day after the last treatment, cell suspensions from the spleens or tumors were filtered, and red blood cells were lysed. For extracellular staining, cells were co-incubated with combinations of antibodies (CD8, CD4, CD11b, Gr-1, CD45, F4/80 and CD206). For intracellular staining, cells were fixed immediately after cell surface staining following the manufacturer's description (eBioscience). Then, combinations of antibodies (IFN-ץ, FoxP3 and granzyme B) were added to cells in permeabilization buffer. For IFN- $\gamma$ staining, cells were stimulated with PMA (5 ng/mL) and ionomycin $(500 \mathrm{ng} / \mathrm{mL})$ in the presence of $10 \mathrm{mg} / \mathrm{mL}$ BFA for $4 \mathrm{~h}$ followed by extracellular and intracellular staining. The data were analyzed using FlowJo software (Tree Star Inc).

\section{Results}

\section{Synthesis and characterization of the PSSN10 polymer}

Supplementary Figure 1 shows the synthesis scheme for the PSSN10 polymer. (i) The hydroxyl group of NLG919 was activated with 4-nitrophenyl chloroformate to give NLG-NO $\mathrm{NO}_{2}$. (ii) The MBC monomer was synthesized according to the literature $^{[23]}$. (iii) POEG $\left(\mathrm{M}_{n}=9 \mathrm{kDa}\right)$ was synthesized by RAFT polymerization as reported previously ${ }^{[24]}$ and further served as a Macro-RAFT agent to initiate polymerization of the MBC monomer. The POEG- $b$-PMBC polymer was obtained after precipitation, which was followed by deprotection of the Bocgroups in TFA/DCM solution to yield the POEG- $b$-PSS polymer. The POEG- $b$-PSSNLG polymer was finally synthesized by the chemical coupling of NLG-NO${ }_{2}$ to the Boc-deprotected POEG- $b$-PSS polymer. The ${ }^{1} \mathrm{H}$ NMR spectrum of the POEG- $b$ PSSNLG polymer is shown in Supplementary Figure S2. Typical peaks at 7.72-7.17, 5.59, 2.04-0.75 ppm were observed in the ${ }^{1} \mathrm{H}$ NMR spectrum of POEG- $b$-PSSNLG and corresponded to the protons of the NLG group. Comparing the intensities of $I_{\mathrm{c}}($ at $5.59 \mathrm{ppm})$ and $I_{\mathrm{a}}($ at $3.39 \mathrm{ppm})$ revealed that 10 NLG units were conjugated on each copolymer, which translated into a DLC of NLG as high as $28 \%(\mathrm{wt})$. The POEG- $b$-PSSNLG prodrug polymer was denoted as PSSN10 in the following study.

\section{Preparation and characterization of blank and DOX-loaded micelles}

PSSN10 prodrug micelles were prepared using a dialysis method. Supplementary Figure S3 shows that the critical micelle concentration (CMC) of PSSN10 was $15.5 \mathrm{mg} / \mathrm{L}$. The relatively low CMC provides good stability of PSSN10 micelles upon dilution in blood. DLS measurements showed that the PSSN10 prodrug micelles had a unimodal size distribution with an average diameter of $134.7 \mathrm{~nm}$ (Figure 1B). After loading of DOX, the particle size increased to $175.1 \mathrm{~nm}$ (Figure 1C). TEM images confirmed the spherical morphology of both PSSN10 micelles and DOX/PSSN10 mixed micelles. DOX was effectively loaded into PSSN10 micelles at a DLC of $4.0 \%$ with a loading efficiency of $84.0 \%$.

In vitro DOX release studies were performed in PBS solution with different GSH concentrations $(0,10 \mu \mathrm{mol} / \mathrm{L}, 10 \mathrm{mmol} / \mathrm{L})$. As shown in Figure 1D, DOX cumulative release from DOX/ PSSN10 mixed micelles was approximately 36\% after $24 \mathrm{~h}$ in the absence of GSH. No acceleration of DOX release was observed in the presence of $10 \mu \mathrm{mol} / \mathrm{L} \mathrm{GSH}$, which mimics the slightly redox environment of the extracellular compartment. However, in the presence of $10 \mathrm{mmol} / \mathrm{L} \mathrm{GSH}$, approximately $70 \%$ of DOX was released within $24 \mathrm{~h}$, indicating that rapid drug release could be achieved in the highly redox environment after intracellular uptake by tumor cells.

\section{In vitro biological activities of PSSN10}

To evaluate the IDO inhibitory effect of the PSSN10 prodrug carrier in vitro, HeLa cells were pretreated with IFN-y to induce IDO expression, and the amount of kynurenine (Kyn) was measured following treatment with PSSN10 and NLG919. As shown in Figure 2A, free NLG919 and PSSN10 blocked 
A

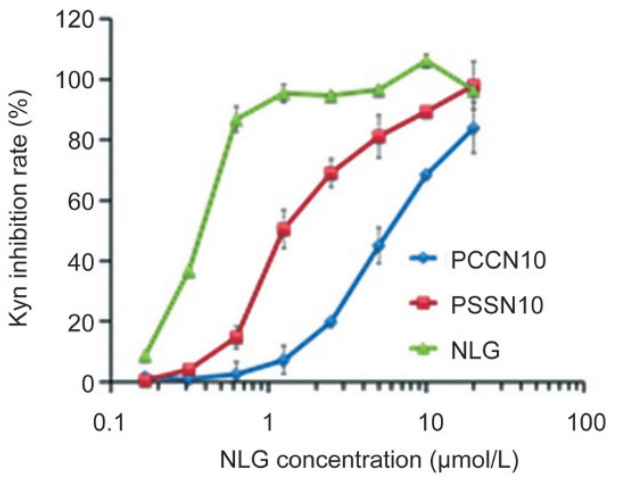

B

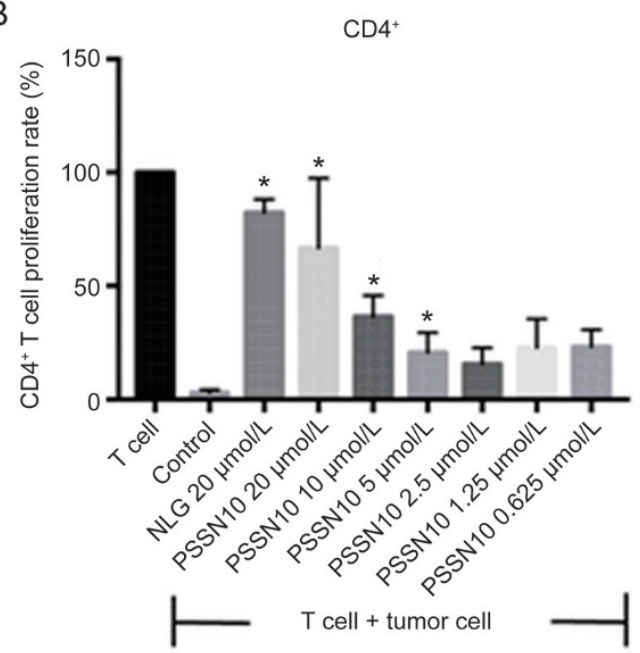

C

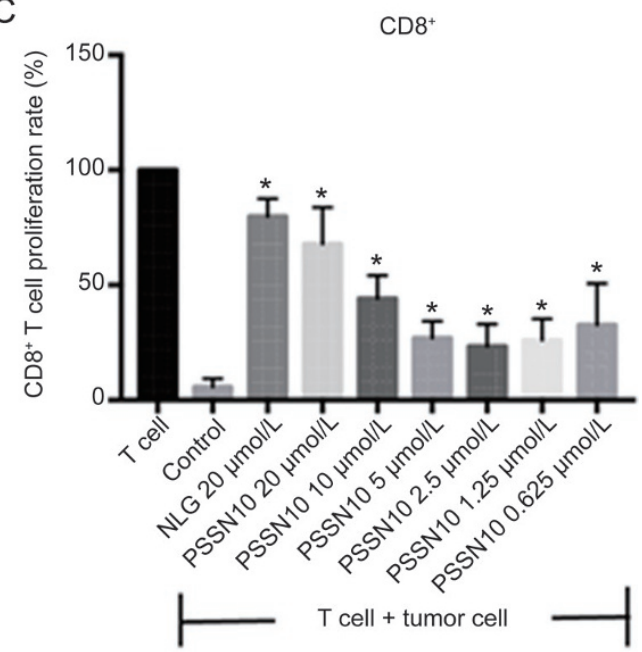

Figure 2. In vitro biological activities of PSSN10. (A) In vitro inhibitory effect of IDO activity. HeLa cells were treated with IFN-y together with PCCN10, PSSN10 and free NLG919. Kynurenine in supernatants was measured $2 \mathrm{~d}$ later. (B) The effect of PSSN10 on reversing T-cell suppression mediated by IDO-expressing mouse pancreatic cancer cells (Panc02). Panc02 cells and splenocytes were mixed and treated with IL-2, anti-CD3 antibody, IFN-Y together with PSSN10 and free NLG919 for $3 \mathrm{~d}$. T-cell proliferation was measured by FACS analysis. ${ }^{*} P<0.05$ (vs control).

IDO function in an NLG concentration-dependent manner, although PSSN10 exhibited a smaller IDO inhibitory effect than free NLG919. We also synthesized PCCN10 polymers without a disulfide linkage (Supplementary Figure S4) as a control. Compared with PCCN10, PSSN10 was more active in inhibiting IDO activity, which might be due to the efficient cleavage of the disulfide linkage in PSSN10 in response to intracellular GSH and suggests the importance of introducing a disulfide linkage into the NLG-based prodrug polymer. Thus, subsequent studies focused on the PSSN10 polymers.

An in vitro lymphocyte-Panc02 (a murine pancreatic cancer cell line) co-culture experiment was then conducted to examine whether T-cell proliferation was enhanced by the IDO inhibitory effect of PSSN10. Figure 2B shows that co-culture of splenocytes isolated from BALB/c mice with $\mathrm{IDO}^{+}$tumor cells led to significant inhibition of the proliferation of both $\mathrm{CD}^{+} \mathrm{T}$ cell and $\mathrm{CD}^{+} \mathrm{T}$ cells. This inhibition was almost completely reversed by free NLG919 at $20 \mu \mathrm{mol} / \mathrm{L}$. Figure 2B also showed that PSSN10 blocked the inhibition by the tumor cells in a concentration-dependent manner. At the same NLG concentration of $20 \mu \mathrm{mol} / \mathrm{L}$, the effect of PSSN10 was comparable to that of free NLG919.

Cytotoxicity and intracellular trafficking of DOX/PSSN10 mixed micelles

MTT assays were performed in 4T1.2 and PC3 cells to evaluate the cytotoxicity of DOX/PSSN10 mixed micelles. As shown in Figure 3A, PSSN10 alone was not effective in inhibiting tumor cell growth. Free DOX exhibited a cytotoxic effect on tumor cells in a concentration-dependent manner. The cytotoxicity of DOX-loaded micelles against 4T1.2 tumor cells was comparable to that of free DOX. Similar results were obtained with the PC3 cell line (Figure 3B).

Intracellular trafficking of DOX-loaded PSSN10 micelles was evaluated in 4 T1.2 cells by confocal laser scanning microscopy with free DOX as a control (Figure 3C). At $4 \mathrm{~h}$ after treatment with free DOX or DOX-loaded PSSN10 micelles, large amounts of fluorescence signals were observed in the perinuclear region of cells. Some of the DOX fluorescence signals were observed in nuclei for cells treated with DOX/PSSN10 mixed micelles, indicating the efficient intracellular delivery of DOX/PSSN10. 
A

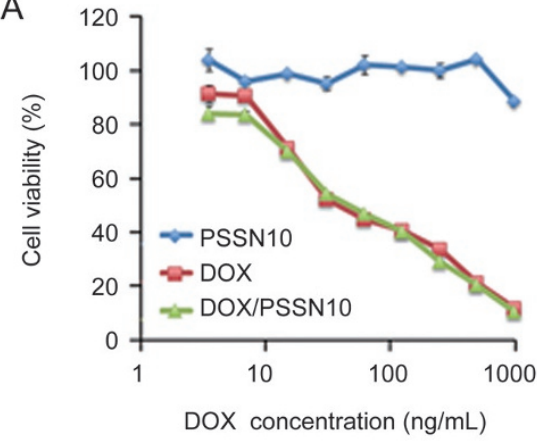

B

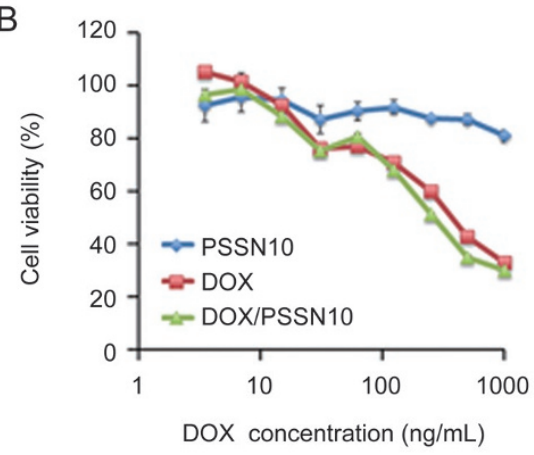

C

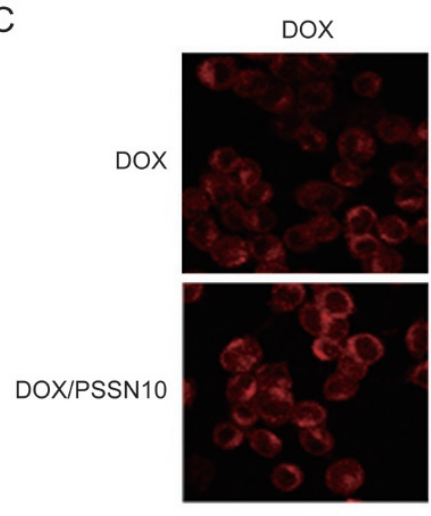

Hoechst
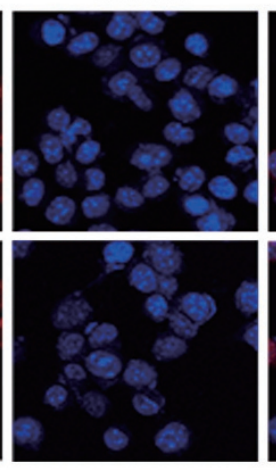

Merged

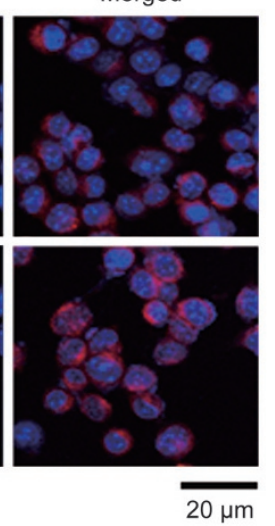

Figure 3. MTT assay of cytotoxicity of PSSN10, DOX and DOX/PSSN10 mixed micelles in (A) 4T1.2 mouse breast cancer cells and (B) PC-3 human prostate cancer cells. Cells were treated for $72 \mathrm{~h}$, and the results are reported as the mean \pm SD for triplicate samples. (C) Confocal laser scanning microscopy images of 4T1.2 cells at $4 \mathrm{~h}$ after treatment with free DOX or DOX/PSSN10 mixed micelles. The nuclei were stained with Hoechst 33342.

\section{Plasma pharmacokinetics and tissue distribution}

Free DOX $\cdot \mathrm{HCl}$ and DOX/PSSN10 mixed micelles $(5 \mathrm{mg}$ $\mathrm{DOX} / \mathrm{kg}$ ) were injected into BALB/c mice, and the DOX concentrations in plasma were measured at different time points. As shown in Figure 4A, DOX/PSSN10 remained in the blood circulation for a significantly longer time than free DOX. The pharmacokinetic parameters were calculated based on a noncompartment model and are outlined in Table 1. The DOX/ PSSN10 formulation showed a significantly higher $T_{1 / 2}$, area under curve $\left(\mathrm{AUC}_{0-\text { inf }}\right)$ and $\mathrm{C}_{\max }$ than free DOX. By contrast, the volume distribution $\left(V_{\mathrm{d}}\right)$ and clearance (CL) of DOX/ PSSN10 were significantly lower than those of free DOX, which suggests a prolonged circulation time of the DOX/ PSSN10 formulation in the blood.

The tissue distributions of both NLG and DOX from DOX/ PSSN10 mixed micelles were also investigated in BALB/C mice bearing $4 \mathrm{~T} 1.2$ tumors. Figure 4B shows the biodistri- bution of NLG at $24 \mathrm{~h}$ following iv administration of DOX/ PSSN10 micelles. Significantly higher concentrations of NLG were detected in the tumors than in other organs/tissues, including the heart, liver, spleen, lung and kidney. In addition, very little NLG was found in the blood, suggesting the good stability of PSSN10 in the blood circulation. Figure 4B shows the biodistribution of DOX at $24 \mathrm{~h}$ following iv administration of DOX/PSSN10 micelles with free DOX as a control. Significantly greater amounts of DOX in tumors were detected for DOX/PSSN10 mixed micelles compared with free DOX. DOX/PSSN10 mixed micelles also showed higher accumulation in tumors than in other organs/tissues. These data suggest that DOX and NLG can be selectively delivered to tumor sites via the PSSN10 prodrug carrier.

\section{In vivo therapeutic study}

Figure 5A shows the in vivo therapeutic effects of PSSN10 and

Table 1. Pharmacokinetic parameters of DOX in different formulations.

\begin{tabular}{lcccr}
\hline Groups & $T_{1 / 2}(\mathrm{~h})$ & $\mathrm{AUC}_{\text {0-infinity }}(\mu \mathrm{g} \cdot \mathrm{h} / \mathrm{mL})$ & $C_{\max }(\mu \mathrm{g} / \mathrm{mL})$ & $\mathrm{CL}\left(\mathrm{L} \cdot \mathrm{h}^{-1} \cdot \mathrm{kg}^{-1}\right)$ \\
\hline DOX/PSSN10 & 10.2 & 47.4 & 23.2 & $V_{\mathrm{d}}(\mathrm{L} / \mathrm{kg})$ \\
DOX & 2.62 & 2.93 & 6.27 & 0.11 \\
\hline
\end{tabular}


A
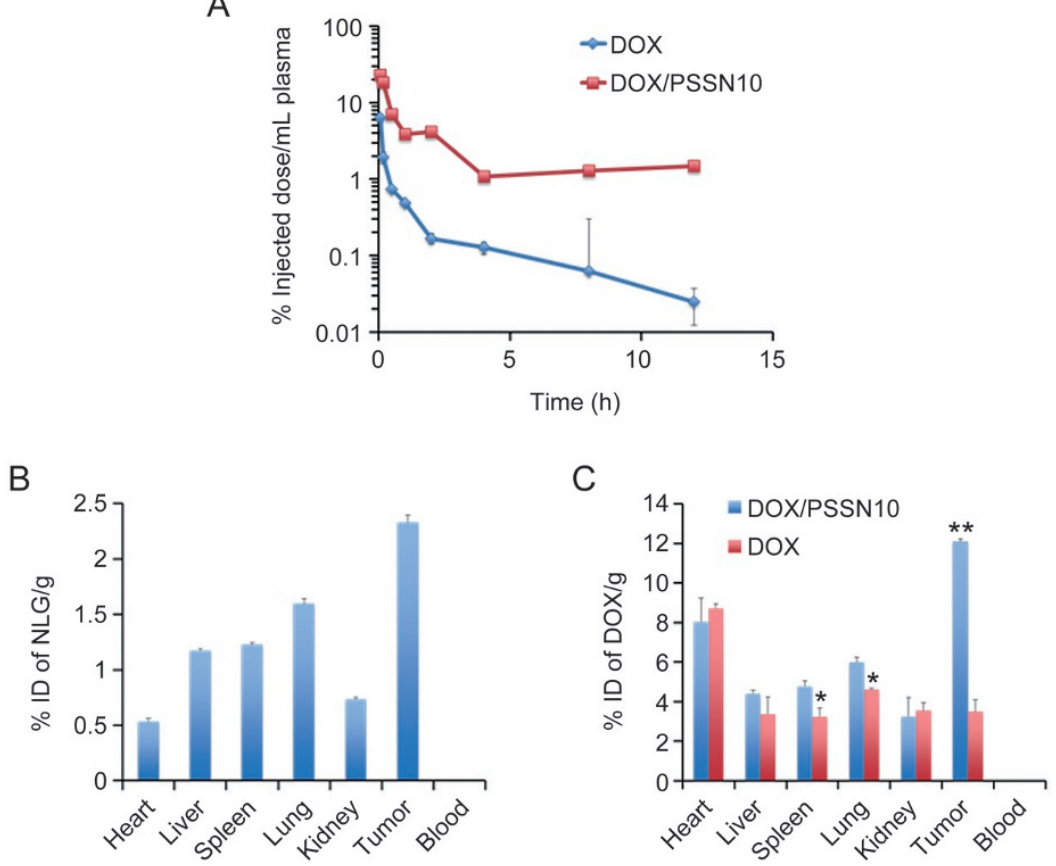

Figure 4. Pharmacokinetics and biodistribution of DOX-loaded PSSN10 micelles. (A) Blood kinetics of DOX in BALB/C mice following iv administration of DOX-loaded PSSN10 micelles at a dose of $5 \mathrm{mg}$ of DOX/kg with free DOX as a control. (B) Tissue distribution of NLG in 4T1.2 tumor-bearing BALB/C mice $24 \mathrm{~h}$ following iv administration of DOX-loaded PSSN10 micelles. (C) Tissue distribution of DOX in 4T1.2 tumor-bearing BALB/c mice $24 \mathrm{~h}$ following iv administration of DOX-loaded PSSN10 or free DOX (5 mg DOX/kg). ${ }^{*} P<0.05,{ }^{* *} P<0.01$ (DOX/PSSN10 vs DOX).

A

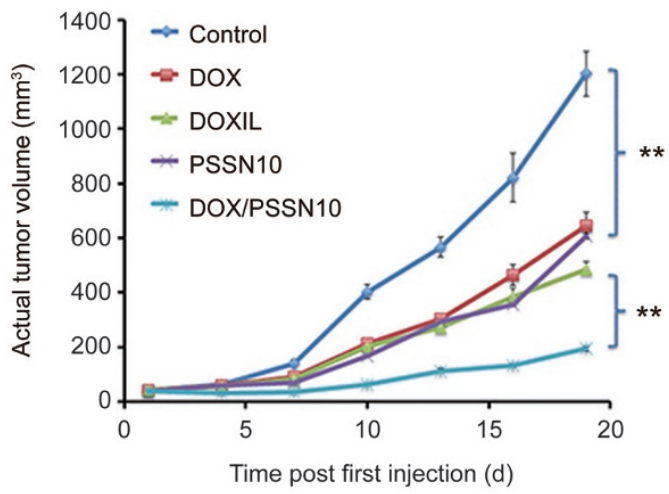

B
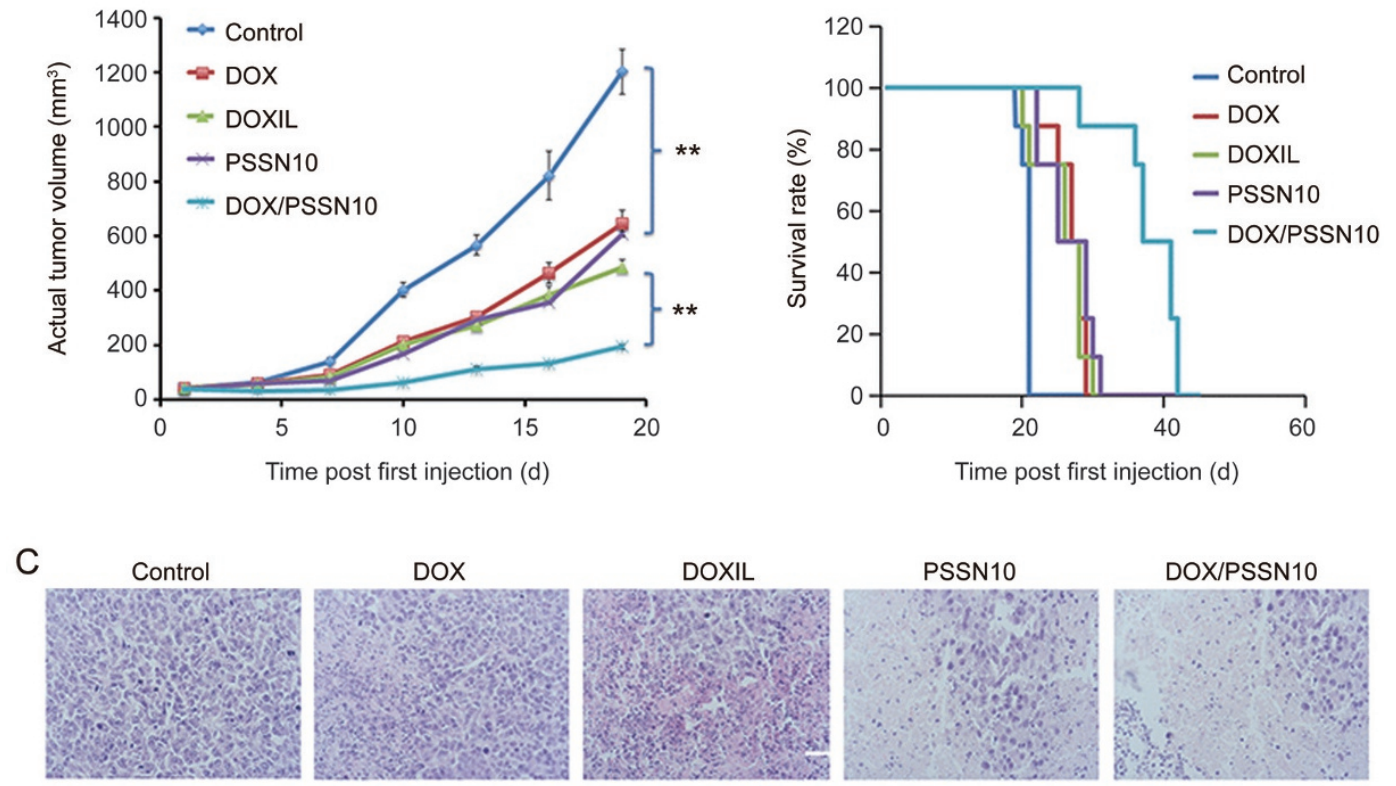

DOXIL

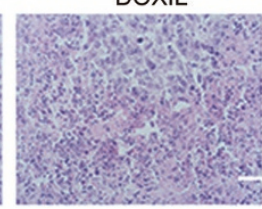

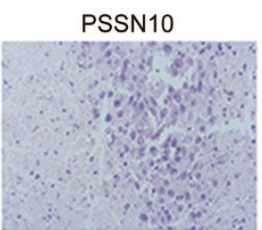

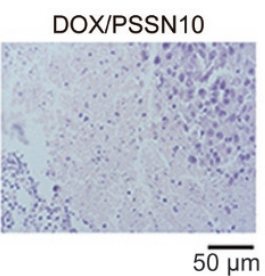

Figure 5. (A) In vivo antitumor activity of PSSN10 and various DOX formulations in a syngeneic murine breast cancer model (4T1.2). Three injections were administered on $\mathrm{d} 0,3$ and $6 .{ }^{* *} P<0.01$. (B) Kaplan-Meier survival of $4 \mathrm{~T} 1.2$ tumor-bearing mice after various treatments. (C) Histological analyses of $\mathrm{H} \& \mathrm{E}$ stained sections of tumor tissues collected on d 19. 
DOX/PSSN10 with free DOX and DOXIL (a clinical formulation of liposomal DOX) as controls $(5 \mathrm{mg} \mathrm{DOX} / \mathrm{kg})$. The PSSN10 carrier alone showed a modest effect in inhibiting tumor growth, comparable to those of DOX and DOXIL. This is in contrast to the in vitro cytotoxicity, in which PSSN10 showed little effect (Figure 3A, 3B), suggesting that the IDO inhibitory effect rather than a direct cytotoxic effect contributed to the in vivo antitumor activity of PSSN10. DOX formulated in PSSN10 micelles showed enhanced antitumor activity that was significantly higher than that of DOXIL.

Figure 5B shows the Kaplan-Meier survival curves of 4T1.2 tumor-bearing mice following different treatments. All formulations improved the survival rate compared to the saline control group. Among them, the DOX/PSSN10 formulation resulted in the longest overall survival, with a median survival of $40 \mathrm{~d}$.

Figure 5C shows the histology of tumors following different treatments. Tumors from the mice treated with DOX/PSSN10 had more necrotic/apoptotic cells compared to the tumors from the other treatment groups.

\section{Effect of DOX/PSSN10 treatment on the tumor immune micro- environment}

The concentrations of Kyn, an indicator of IDO enzyme activity, in tumor tissue and blood following the various treatments were measured by HPLC-MS. As shown in Figure 6, the Kyn concentrations in both blood and tumors were significantly decreased following treatment with PSSN10 and DOX/ PSSN10, respectively. Interestingly, the levels of Kyn in the blood were also significantly decreased in mice treated with DOXIL.
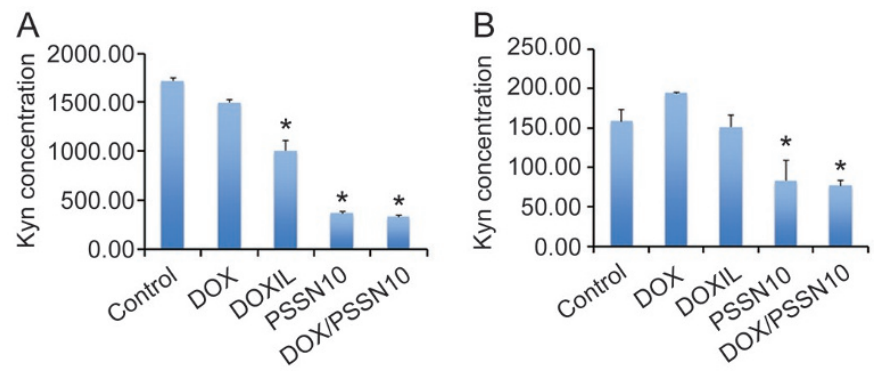

Figure 6. Kynurenine concentrations in (A) tumor and (B) blood of BALB/C mice bearing s.c. $4 \mathrm{~T} 1.2$ tumors following various treatments. ${ }^{*} P<0.05$ (vs control).

We then further examined changes in the immune cell subpopulation in the tumor tissues of the mice that received different treatments. As shown in Figure 7A, PSSN10 treatment led to a significant increase in the relative numbers of $\mathrm{CD}^{+} \mathrm{T}$ cells and $\mathrm{CD}^{+} \mathrm{T}$ cells in the tumors compared with the control, DOX or DOXIL groups. There was no significant difference in the relative numbers of $\mathrm{CD}^{+} \mathrm{T}$ cells between PSSN10 and DOX/PSSN10 (Figure 7A).

Figure $7 \mathrm{~B}$ shows that the relative number of granzyme
B-positive $\mathrm{CD}^{+} \mathrm{T}$ cells in tumors was increased in all treatment groups compared with the control group. The relative number of granzyme B-positive $\mathrm{CD}^{+} \mathrm{T}$ cells in tumor tissues was higher in the groups treated with PSSN10 or DOX/ PSSN10 than in the DOX-treated group. No significant difference was found in the relative number of granzyme B-positive $\mathrm{CD}^{+} \mathrm{T}$ cells between the PSSN10 and DOX/PSSN10 groups.

Figure 7C shows that the relative cell number of regulatory $\mathrm{T}$ cells (Treg) was reduced in all treatment groups compared with the control group. Similarly, the relative cell number of granulocytic myeloid-derived suppressor cells (G-MDSCs) in the tumors was reduced in all treatment groups (Figure 7D). No significant difference was found in the relative cell number of Treg cells (Figure 7C) or G-MDSCs (Figure 7D) between the PSSN10 and DOX/PSSN10 groups. There was also a slight decrease in the relative cell number of monocytic MDSCs (M-MDSCs) in the tumors after various treatments (Figure 7D).

Figure 7E shows that the relative cell number of M1

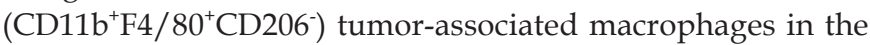
tumors was slightly increased in all treatment groups. By contrast, the relative cell number of $\mathrm{M} 2\left(\mathrm{CD} 11 \mathrm{~b}^{+} \mathrm{F} 4 / 80^{+} \mathrm{CD} 206^{+}\right)$ tumor-associated macrophages was significantly reduced following treatment with DOXIL, PSSN10 or DOX/PSSN10.

Overall, these data suggest a more immunoactive tumor microenvironment in mice treated with PSSN10 or DOX/ PSSN10 compared with the control or other treatment groups. This conclusion is consistent with the greater in vivo IDO inhibitory effect of DOX/PSSN10 compared with DOXIL or the other groups (Figure 6).

\section{Discussion}

Checkpoint blockade immunotherapy has been developed as a promising treatment modality for various malignancies ${ }^{[31,32]}$. Currently, immune checkpoint blockade is achieved with monoclonal antibodies specific for different immune checkpoint proteins ${ }^{[33]}$. Recently, there has been growing interest in developing small-molecule immune checkpoint inhibitors ${ }^{[34,35]}$. Compared to antibody-based immunotherapeutics, smallmolecule checkpoint inhibitors have the advantages of excellent safety, ease of production and more efficient delivery into the tumor site $\mathrm{e}^{[35]}$.

IDO1 is an important immune checkpoint protein that suppresses $\mathrm{T}$ cell proliferation through Trp catabolism and Kyn production. 1-Methyl-d-tryptophan (1-MT) and NLG919 are two important small-molecule inhibitors with distinct mechanisms for blocking IDO1-mediated tumor immune escape ${ }^{[36]}$. Compared to 1-MT, NLG919 is a more potent IDO1-selective inhibitor, with an EC50 of $75 \mathrm{nmol} / \mathrm{L}^{[37]}$. Some studies have shown that IDO inhibitors can improve the therapeutic efficacy of chemotherapy or work synergistically with chemotherapy ${ }^{[18,19]}$. However, there is limited information about combination therapy of NLG919 with a chemotherapeutic drug ${ }^{[38]}$.

Our group previously developed a PEG-NLG conjugate (PEG2k-Fmoc-NLG) as a prodrug nanocarrier for co-delivery of NLG919 and paclitaxel (PTX), a commonly used chemo- 
A

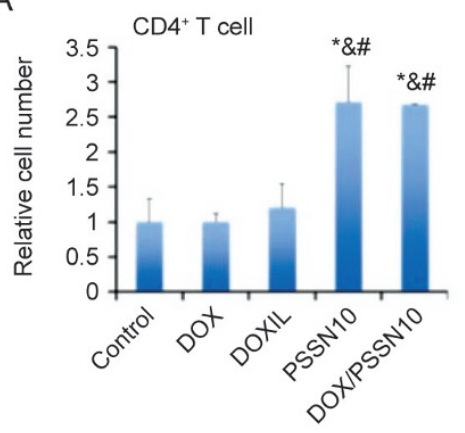

C

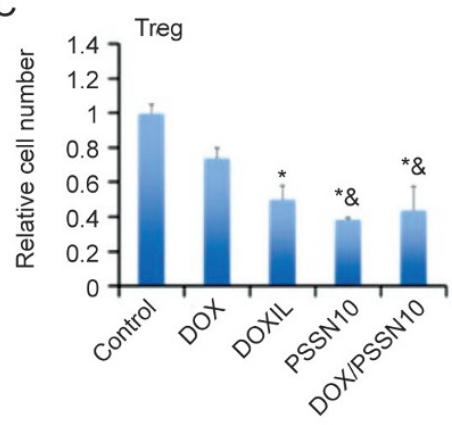

E

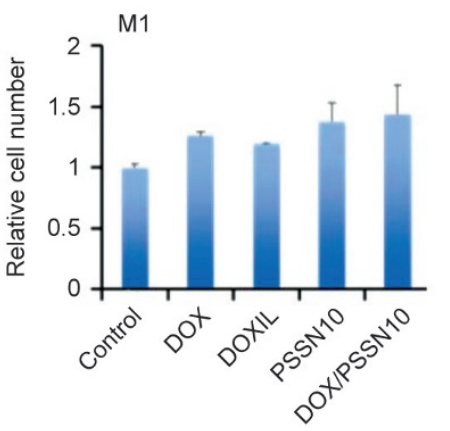

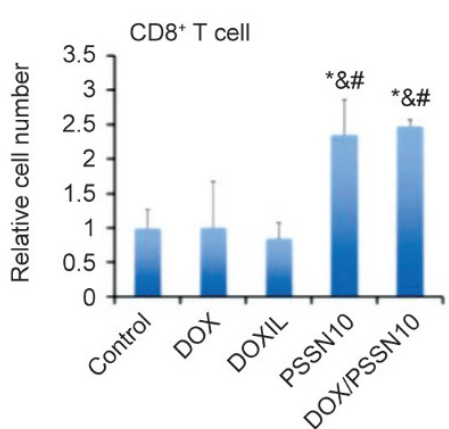

B

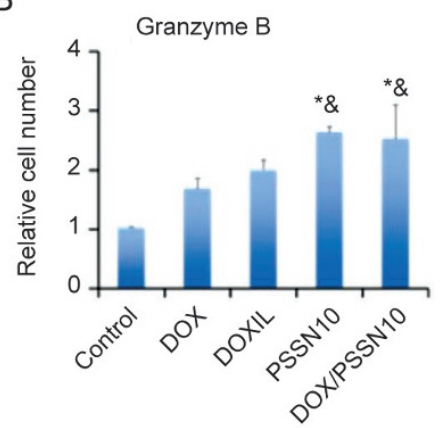

D
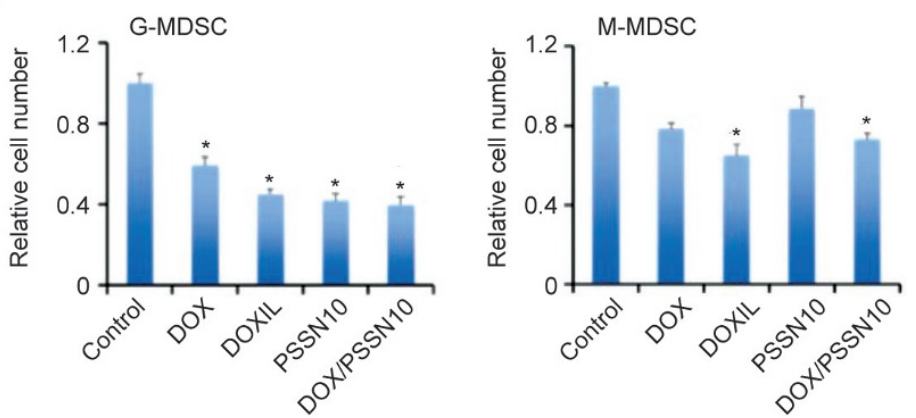

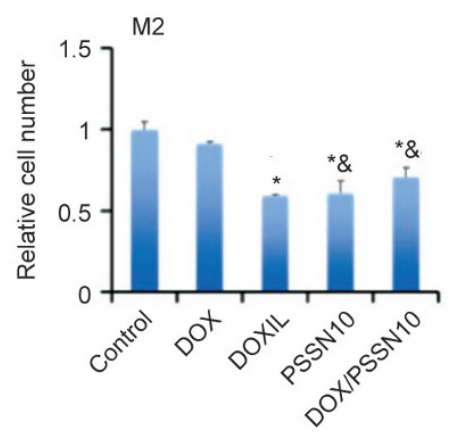

Figure 7. Flow cytometry analysis of immune cell subsets in tumor tissues. Tumor bearing mice received various treatments at a DOX dosage of 5 $\mathrm{mg} / \mathrm{kg}$ for three times at an interval of $3 \mathrm{~d}$ and tumoral T-cell infiltration, including (A) $\mathrm{CD} 4^{+}$and $\mathrm{CD} 8^{+},(\mathrm{B})$ granzyme B-positive CD8 ${ }^{+} \mathrm{T}$ cells, were measured by flow cytometry. (C) FoxP3 ${ }^{+} \mathrm{T}$ regulatory cells, (D) MDSC subsets (Gr- $1^{\text {high }} \mathrm{CD} 11 \mathrm{~b}^{+}$granulocytic $(\mathrm{G}-\mathrm{MDSC})$ and Gr- $1^{\text {int }} \mathrm{CD} 11 \mathrm{~b}^{+}$monocytic (M-MDSC)) and (E) tumor-associated macrophage (TAM) populations (M1-type (CD11 b $\left./ F 4 / 80^{+} / \mathrm{CD} 206\right)$ and $\mathrm{M}^{-}$-type $\left.\left(\mathrm{CD} 11 \mathrm{~b}^{+} / \mathrm{F} 4 / 80^{+} / \mathrm{CD}^{-} 06^{+}\right)\right)$were also detected by flow cytometry. The bars represent means \pm SEM. ${ }^{*} P<0.05$ (vs control); ${ }^{\circledR} P<0.05$ (vs DOX); ${ }^{\#} P<0.05$ (vs DOXIL).

therapeutic drug ${ }^{[20]}$. The immune-enhancing function of NLG and the tumor-killing effect of PTX synergistically contributed to the increased anti-tumor efficacy. In this work, we further improved the NLG-based prodrug carrier system by increasing the number of NLG units per carrier molecule via RAFT polymerization. Compared to the previous system, the NLG loading content in the new PSSN10 system increased from $9.4 \%$ to $19.7 \%$, which could help decrease the amounts of carrier materials for in vivo application. In addition, a disulfide linkage was introduced in the PSSN10 system to promote the release of NLG from the prodrug carrier (data not shown).

PSSN10 readily formed small-sized micelles capable of loading various types of anticancer agents, including DOX, PTX, docetaxel and curcumin (data not shown). We focused on DOX in this work because DOX can elicit caspase-dependent immunogenicity and enhance the proliferation of tumor anti- gen-specific $\mathrm{CD}^{+} \mathrm{T}$ cells in tumor-draining lymph nodes ${ }^{[39-42]}$. A recent study demonstrated that the effectiveness of immune checkpoint blockade is dependent on preexisting antitumor immunity ${ }^{[3]}$. In addition, it has been reported that postchemotherapy delivery of immunotherapy is a more effective treatment mode in inhibiting tumor progression ${ }^{[43]}$. Therefore, combining PSSN10 with DOX, which is capable of inducing immunogenic tumor cell death, represents a rational approach for cancer immunochemotherapy.

One unique feature of our approach is the programmable release of NLG and DOX to maximize the efficacy of the combination therapy. DOX was physically loaded into PSSN10 micelles and rapidly released from the micelles upon reaching the tumor site. DOX-mediated killing of tumor cells and/or the direct effect of DOX on immune cells could lead to enhanced tumor antigen presentation and improved 
antitumor immunity. By contrast, NLG was covalently linked to the polymer and was released at a relatively slower pace, which would help maintain or enhance the anti-tumor immune response over a prolonged period of time by reversing IDO-mediated immune suppression. Indeed, DOX/ PSSN10 mixed micelles were significantly more effective than DOXIL or free DOX in inhibiting the tumor growth and prolonging the survival of treated mice. The superior antitumor activity of DOX/PSSN10 mixed micelles is likely due to the effective delivery of both NLG and DOX to the tumor tissue as demonstrated in the biodistribution study (Figure 4). The synergistic action between DOX and released NLG may also play an important role.

The immunological analysis indicated that tumor tissues from mice treated with PSSN10 were more immunoactive, with a higher percentage of functional T cells $\left(\mathrm{CD} 4^{+}\right.$and $\left.\mathrm{CD} 8^{+}\right)$ and lower percentages of Treg cells and MDSCs compared with untreated tumors or tumors treated with DOX or DOXIL (Figure 7). Incorporation of DOX into the PSSN10 system did not affect the function of PSSN10 in enhancing T cell proliferation and suppressing Treg cells and G-MDSCs. By contrast, our previous study of the PTX-loaded PEG2k-Fmoc-NLG system showed that incorporation of PTX led to a reduction in the percentage of total intratumoral $\mathrm{T}$ cells and an increase in the percentage of MDSC cells compared to PEG2k-Fmoc-NLG alone $^{[43]}$. It is not clear if this divergence is due to the differences in drugs or the dosages of the drugs in the two different studies. More studies are needed to better understand the underlying mechanisms.

In conclusion, we have developed a new redox-sensitive system, PSSN10, for programmable co-delivery of DOX and NLG. Our data suggest that DOX/PSSN10 has potential as an effective combination regime for cancer immunochemotherapy.

\section{Acknowledgements}

This work was supported by NIH grants RO1CA173887, RO1GM102989, and R21CA173887.

\section{Author contribution}

Jing-jing SUN and Yi-chao CHEN contributed equally. Study concept and design: Song LI, Jing-jing SUN and Yi-xian HUANG; chemical synthesis and micelle characterization: Jing-jing SUN; biological study: Yi-chao CHEN, Jing-jing SUN and Yan-hua LIU; analysis of data: Yi-chao CHEN, Jing-jing SUN and Wen-chen ZHAO; drafting of the manuscript: Jingjing SUN and Song LI.

\section{Supplementary information}

Supplementary information is available on the website of Acta Pharmacologica Sinica.

\section{References}

1 Zitvogel L, Apetoh L, Ghiringhelli F, Kroemer G. Immunological aspects of cancer chemotherapy. Nat Rev Immunol 2008; 8: 59-73.

2 Sharon E, Streicher H, Goncalves P, Chen HX. Immune checkpoint inhibitors in clinical trials. Chin J Cancer 2014; 33: 434-44.
3 Pardoll DM. The blockade of immune checkpoints in cancer immunotherapy. Nat Rev Cancer 2012; 12: 252-64.

4 Perkins D, Wang Z, Donovan C, He H, Mark D, Guan G, et al. Regulation of CTLA-4 expression during T cell activation. J Immunol 1996; 156: 4154-9.

5 Contardi E, Palmisano GL, Tazzari PL, Martelli AM, Fala F, Fabbi M, et al. CTLA-4 is constitutively expressed on tumor cells and can trigger apoptosis upon ligand interaction. Int J Cancer 2005; 117: 538-50.

6 Topalian SL, Drake CG, Pardoll DM. Immune checkpoint blockade: a common denominator approach to cancer therapy. Cancer Cell 2015; 27: 450-61.

7 Blank C, Mackensen A. Contribution of the PD-L1/PD-1 pathway to T-cell exhaustion: an update on implications for chronic infections and tumor evasion. Cancer Immunol Immunother 2007; 56: 739-45.

8 Okazaki T, Honjo T. The PD-1-PD-L pathway in immunological tolerance. Trends Immunol 2006; 27: 195-201.

9 Ribas A. Releasing the brakes on cancer immunotherapy. N Engl J Med 2015; 373: 1490-2.

10 Da Silva C, Rueda F, Löwik C, Ossendorp F, Cruz LJ. Combinatorial prospects of nano-targeted chemoimmunotherapy. Biomaterials 2016; 83: 308-20.

11 Apetoh L, Ladoire S, Coukos G, Ghiringhelli F. Combining immunotherapy and anticancer agents: the right path to achieve cancer cure? Ann Oncol 2015; 26: 1813-23.

12 Xiao Y, Freeman GJ. The microsatellite instable subset of colorectal cancer is a particularly good candidate for checkpoint blockade immunotherapy. Cancer Discov 2015; 5: 16-8.

13 Curti A, Trabanelli S, Salvestrini V, Baccarani M, Lemoli RM. The role of indoleamine 2, 3-dioxygenase in the induction of immune tolerance: focus on hematology. Blood 2009; 113: 2394-401.

14 Hwu P, Du MX, Lapointe R, Taylor MW, Young HA. Indoleamine 2,3-dioxygenase production by human dendritic cells results in the inhibition of T cell proliferation. J Immunol 2000; 164: 3596-9.

15 Munn DH, Mellor AL. IDO in the tumor microenvironment: inflammation, counter-regulation, and tolerance. Trends Immunol 2016; 37: 193-207.

16 Smith C, Chang MY, Parker KH, Beury DW, DuHadaway JB, Flick HE, et al. IDO is a nodal pathogenic driver of lung cancer and metastasis development. Cancer Discov 2012; 2: 722-35.

17 Nayak A, Hao Z, Sadek R, Vahanian N, Ramsey WJ, Kennedy E, et al. A Phase I study of NLG919 for adult patients with recurrent advanced solid tumors. J Immunother Cancer 2014; 2: 250.

18 Awuah SG, Zheng YR, Bruno PM, Hemann MT, Lippard SJ. A Pt (IV) pro-drug preferentially targets indoleamine-2,3-dioxygenase, providing enhanced ovarian cancer immuno-chemotherapy. J Am Chem Soc 2015; 137: $14854-7$.

19 Muller AJ, DuHadaway JB, Donover PS, Sutanto-Ward E, Prendergast GC. Inhibition of indoleamine 2,3-dioxygenase, an immunoregulatory target of the cancer suppression gene Bin1, potentiates cancer chemotherapy. Nat Med 2005; 11: 312-9.

20 Chen Y, Xia R, Huang Y, Zhao W, Li J, Zhang X, et al. An immunostimulatory dual-functional nanocarrier that improves cancer immunochemotherapy. Nat Commun 2016; 7: 13443.

21 Casares N, Pequignot MO, Tesniere A, Ghiringhelli F, Roux S, Chaput $\mathrm{N}$, et al. Caspase-dependent immunogenicity of doxorubicin-induced tumor cell death. J Exper Med 2005; 202: 1691-701.

22 Sun J, Luo T, Sheng R, Li H, Chen S, Hu F, et al. Preparation of functional water-soluble low-cytotoxic poly(methacrylate)s with pendant cationic I-lysines for efficient gene delivery. Macromol Biosci 2013; 13: 35-47.

23 Sun P, Zhou D, Gan Z. Novel reduction-sensitive micelles for triggered 
intracellular drug release. J Control Release 2011; 155: 96-103.

24 Sun J, Chen Y, Li K, Huang Y, Fu X, Zhang X, et al. A prodrug micellar carrier assembled from polymers with pendant farnesyl thiosalicylic acid moieties for improved delivery of paclitaxel. Acta Biomater 2016; 43: 282-91.

25 Sun J, Luo T, Sheng R, Li H, Wang Z, Cao A. Intracellular plasmid DNA delivery by self-assembled nanoparticles of amphiphilic PHML-b-PLLAb-PHML copolymers and the endocytosis pathway analysis. J Biomater Appl 2016; 31: 606-21.

26 Liu X, Shin N, Koblish HK, Yang G, Wang Q, Wang K, et al. Selective inhibition of IDO1 effectively regulates mediators of antitumor immunity. Blood 2010; 115: 3520-30.

27 Hou DY, Muller AJ, Sharma MD, DuHadaway J, Banerjee T, Johnson $\mathrm{M}$, et al. Inhibition of indoleamine 2, 3-dioxygenase in dendritic cells by stereoisomers of 1-methyl-tryptophan correlates with antitumor responses. Cancer Res 2007; 67: 792-801.

28 Lu J, Zhao W, Liu H, Marquez R, Huang Y, Zhang Y, et al. An improved d- $\alpha$-tocopherol-based nanocarrier for targeted delivery of doxorubicin with reversal of multidrug resistance. J Control Release 2014; 196: 272-86.

29 Koblish HK, Hansbury MJ, Bowman KJ, Yang G, Neilan CL, Haley PJ, et al. Hydroxyamidine inhibitors of indoleamine-2,3-dioxygenase potently suppress systemic tryptophan catabolism and the growth of IDOexpressing tumors. Mol Cancer Ther 2010; 9: 489-98.

30 Broz ML, Binnewies M, Boldajipour B, Nelson AE, Pollack JL, Erle DJ, et al. Dissecting the tumor myeloid compartment reveals rare activating antigen-presenting cells critical for T cell immunity. Cancer Cell 2014; 26: 638-52.

31 Haanen JB, Robert C. Immune checkpoint inhibitors. ImmunoOncology. Karger Publishers. 2015. p 55-66.

32 Brahmer JR, Pardoll DM. Immune checkpoint inhibitors: making immunotherapy a reality for the treatment of lung cancer. Cancer Immunol Res 2013; 1: 85-91.

33 Weber J. Immune checkpoint proteins: a new therapeutic paradigm for cancer-preclinical background: CTLA-4 and PD-1 blockade. Semin Oncol 2010; 37: 430-9.

34 Cheng T, Liu Z, Wang R. A knowledge-guided strategy for improving the accuracy of scoring functions in binding affinity prediction. BMC Bioinformatics 2010; 11: 193.
35 Barakat KH. Do We Need Small Molecule Inhibitors for the Immune Checkpoints? J Manag Pharm Care 2014; 1: 1000e119.

36 Muller AJ, Malachowski WP, Prendergast GC. Indoleamine 2,3-dioxygenase in cancer: targeting pathological immune tolerance with smallmolecule inhibitors. Expert Opin Ther Targets 2005; 9: 831-49.

37 Qian S, Zhang M, Chen Q, He Y, Wang W, Wang Z. IDO as a drug target for cancer immunotherapy: recent developments in IDO inhibitors discovery. RSC Advances 2016; 6: 7575-81.

38 Murphy AG, Zheng L. Small molecule drugs with immunomodulatory effects in cancer. Hum Vaccin Immunother 2015; 11: 2463-8.

39 Ma Y, Aymeric L, Locher C, Mattarollo SR, Delahaye NF, Pereira P, et al. Contribution of IL-17-producing gamma delta T cells to the efficacy of anticancer chemotherapy. J Exp Med 2011; 208: 491-503.

40 Galluzzi L, Senovilla L, Zitvogel L, Kroemer G. The secret ally: immunostimulation by anticancer drugs. Nat Rev Drug Discov 2012; 11 : 215-33.

41 Kim JE, Jang MJ, Lee JI, Chung YH, Jeong JH, Hung CF, et al. Cancer cells containing nanoscale chemotherapeutic drugs generate antiovarian cancer-specific $\mathrm{CD} 4^{+} \mathrm{T}$ cells in peritoneal space. J Immunother 2012; 35: 1-13.

42 Rios-Doria J, Durham N, Wetzel L, Rothstein R, Chesebrough J, Holoweckyj N, et al. Doxil synergizes with cancer immunotherapies to enhance antitumor responses in syngeneic mouse models. Neoplasia 2015; 17: 661-70.

43 Lake RA, Robinson BW. Immunotherapy and chemotherapy - a practical partnership. Nat Rev Cancer 2005; 5: 397-405.

This work is licensed under the Creative Commons Attribution-NonCommercial-No Derivative Works 3.0 Unported License. To view a copy of this license, visit http://creativecommons.org/licenses/ by-nc-nd/3.0/

(C) The Author(s) 2017 